\title{
DOES THE INTAKE OF LC-PUFAS DURING PREGNANCY AFFECT THE BODY COMPOSITION OF TERM NEONATES? PRELIMINARY RESULTS
}

\author{
T. Camões ${ }^{1}$, A. Silva ${ }^{1}$, R. Neves ${ }^{2}$, L. Pereira-da-Silva ${ }^{1,2,3}$, A.C. Moreira ${ }^{1}$, D. Virella ${ }^{3,4}$, M. Alves ${ }^{4}$, A.L.

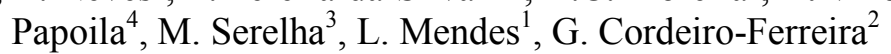 \\ ${ }^{1}$ Licenciatura em Dietética e Nutrição, Escola Superior de Tecnologia da Saúde de Lisboa, IPL, \\ ${ }^{2}$ Laboratório de Nutrição do Hospital de Dona Estefânia, Centro Hospitalar de Lisboa Central, ${ }^{3}$ Neonatal \\ Intensive Care Unit, Hospital de Dona Estefânia, Centro Hospitalar de Lisboa Central, ${ }^{4}$ Gabinete de Apoio \\ Epidemiológico e Estatístico, Centro de Investigação, Centro Hospitalar de Lisboa Central, Lisboa, \\ Portugal
}

Background: The effect of the intake of polynsaturated long chain fatty acids (LCPUFAs) during pregnancy on fetal body composition has been assessed by studies using mostly neonatal anthropometry. Their results have been inconsistent, probably because neonatal anthropometry has several validity limitations. Air displacement plethismography (ADP) is a recently validated non-invasive method for assessing body composition in neonates.

Objective: To determine the effect of the intake of LCPUFAs during pregnancy on the body composition of term neonates, measured by ADP.

Methods: Cross-sectional study of a convenience sample of healthy full-term neonates and their mothers. The diet during pregnancy was assessed using a validated semi-quantitative food frequency questionnaire; Food Processor Plus ${ }^{\circledR}$ was used to convert food intake into nutritional values. Body composition was estimated by anthropometry and measured by ADP using Pea Pod ${ }^{\mathrm{TM}}$ Life Measurements Inc (fat mass - FM, fat-free mass and $\% \mathrm{FM}$ ) within the first $72 \mathrm{~h}$ after birth. Univariate and multivariate analysis (linear regression model) were performed.

Results: 54 mother-neonate pairs were included. Multivariate analysis adjusted to the maternal body mass index shows positive association between LCPUFAs intake and neonatal mid-arm circumference $(=0,610, p$ $=0,019)$ and negative association between $n-6: n-3$ ratio intake and neonatal $\% \mathrm{FM}(=-2,744, \mathrm{p}=0,066)$.

Conclusion: To the best of our knowledge, this is the first study on this subject using ADP and showing a negative association between LCPUFAs $n-6: n-3$ ratio intake in pregnancy and neonatal \%FM. This preliminary finding requires confirmation increasing the study power with a greater sample and performing interventional studies. 